\title{
VÓS SOIS O SAL DA TERRA E A LUZ DO MUNDO
}

\author{
You are the salt of the Earth and light of the World
}

\author{
Thiago Zanetti*
}

\section{RESUMO}

Este artigo tem por objetivo destacar a importância da ação evangelizadora por parte dos cristãos. Temos a intenção de alertar sobre o estado deletério que é o comodismo, a antiação para a transformação de uma sociedade mais justa, fraterna e cristã. Somente cristãos novos, isto é, revestidos com a força do Alto, imbuídos pelo sopro criativo do Espírito Santo de Deus podem mudar o estado de coisas atuais. Para que o mundo mude, é necessário que cada um, em sua condição, dons e talentos, sejam um outro Cristo na terra.

Palavras-chave: Cristão. Ação. Sociedade. Omissão. Anúncio.

\section{ABSTRACT}

This article aims to emphasize the relevance of Christians' actions, as protagonists of evangelization. We intend to make you aware of how horrible can be the complacency and the non action for society. It can stop better changes and some transformations to a more fair, fraternal and Christian society. Only the new Christians, by this we mean, the ones replete with a strength coming from Heaven, full filled/ imbued by the creative blow of the Holy Spirit of God, can change the current reality. But, to make this happen, it is necessary that each one, in your on conditions, gifts and talents, be other Christ on Earth.

Keiwords: Christian. Action. Socity. Omission. Ad.

* Graduado em Jornalismo (2003) e Mestre em História Social das Relações Políticas (2007), ambos pela Universidade Federal do Espírito Santo (UFES). É fundador do Portal C3press.com (www.c3press.com). Escreve para a revista Ave-Maria, primeira revista mariana do Brasil. E-mail: <contato@c3press.com>.

\begin{tabular}{|l|l|l|l|l|l|}
\hline Teocomunicação & Porto Alegre & v. 44 & n. 2 & p. 294-302 & maio-ago. 2014 \\
\hline
\end{tabular}




\section{Introdução}

Muitas vezes falamos que o mundo está de ponta cabeça - e de fato está! - que a maldade, a indiferença, um sistema perverso e pervertido está tomando conta das mentalidades. Mas é preciso, antes, perguntar-se: o que estou fazendo para mudar tudo isso? Como enfatizamos no texto: não há como ser cristão e não ser comprometido com a sociedade, com a melhoria de vida das pessoas e que as palavras cristão, ação, mudança, amor, paz, perdão, unção, entre outras, não se separam; se você se disser cristão e não vive a ação, o amor, o perdão a transformação da sociedade, você será uma caricatura de cristão, um falso cristão.

\section{Ser Sal e Luz do Mundo}

Deus não precisa do homem para agir no mundo Ele é Deus, e tudo pode; mas quis contar com a nossa participação.

Não temos outra escolha: ou ser luz no mundo, ou deixar o terreno livre para o mal tomar conta deste planeta.

Não podemos ficar sentados no sofá ou deitados numa cama, vendo o dia passar, assistindo à televisão, esquentando o banco da Igreja como se tudo estivesse bem. Pior do que dizer que o mundo está sujo, corrompido, à beira da ruína devido ao descaso e à maldade dos homens, é não fazer nada para mudar essa situação e cruzar os braços.

Omitir-se, não fazer absolutamente nada para mudar o mundo, o nosso bairro, a nossa cidade, o nosso estado, o nosso país, é acovardarse. Devemos lutar por causas nobres, isto é, por todos que necessitam de alguma ajuda, rico ou podre; não nos deixarmos abater pela maldade que impera no planeta.

Nada fazer para mudar a realidade é entregar o ouro para o bandido, é permitir que pessoas mal-intencionadas, ruins, tramem contra o bem e tomem conta do espaço que deveria ser ocupado por um homem e uma mulher de bem, por um seguidor de Jesus.

Tudo que existe no mundo foi santificado e abençoado por Deus. Ao criar o mundo, "Deus viu tudo quanto havia feito e achou que era bom" ( Gn 1,31a). O mundo é de Deus e não do inimigo; o mundo está torto, sujo e corrompido, pervertido por nossa culpa; precisamos endireitá-lo. De que maneira? Dizendo o 'sim' que Maria deu para os projetos de Deus; usando nossos dons e carismas, talentos, nossa profissão, aptidões 
naquilo que sabemos fazer, e arregaçar as mangas, porque "a fé, sem a prática, é morta" $(\operatorname{Tg} 2,26)$.

A união de todos num projeto comum é fundamental; juntos somos mais fortes. É certo que a mudança do mundo começa primeiro em nós, com a conversão de nosso coração, porque um coração sujo, sem fé, no pecado, sem Cristo, nada pode fazer; primeiro, devemos ter o coração limpo, e isso se faz orando a Deus que nos limpe.

Dada a conversão, isto é, uma mudança de postura diante da vida, uma mudança de mentalidade e de atitude, o rompimento com todo o pecado, o segundo passo é agregar pessoas, aglutinar homens e mulheres que deem o seu sim para mudar a realidade.

O ditado popular afirma que uma andorinha não faz verão; e não o faz mesmo! No entanto, voando em bando de milhares, essa ave anuncia a mudança de estação. A historinha do beija-flor mostra que ele tentou apagar o fogo da floresta. Chamado de louco, disse que estava fazendo a sua parte. Assim também deve ser o cristão. Passada a primeira etapa da conversão, a tarefa seguinte é juntar, reunir, arregimentar, integrar, incorporar outras pessoas com ideais e projetos éticos, morais, a favor da vida, com consonância com as Sagras Escrituras; uma mentalidade cristã.

A Primeira Carta de S. João anuncia que "o mundo inteiro está sob o poder do Maligno" ( $\left.1 J_{o} 5,19\right)$, mas Jesus nos diz: "Tende coragem, eu venci o mundo" (Jo 16,33b); e S. Paulo nos dá o brado da vitória: "Somos mais que vencedores, graças àquele que nos amou" $(R m 8,37)$.

O mundo está de cabeça para baixo porque estamos trabalhando pouco e fazendo pouco do que Jesus nos pede! Omitimo-nos, corremos do pau, não empreitamos uma vida aguerrida que nos chama a sermos cristãos comprometidos, e isso não é mais do que nossa obrigação. Não há como ser cristão e não ser comprometido com a sociedade, com a melhoria de vida das pessoas. Jesus, o maior reformador que o planeta já conheceu, um líder sem igual, o maior advogado, o médico dos médicos, reformou a nossa cidade interior e, a partir daí, a realidade local, social pôde ser mudada.

As palavras cristão, ação, mudança, amor, paz, perdão, unção, entre outras, não se separam; se você se disser cristão e não vive a ação, o amor, o perdão a transformação da sociedade, você será uma caricatura de cristão, um falso cristão.

Algo importante cuja ausência deixa todo o nosso trabalho em vão é o Evangelho de Cristo. Precisamos passar pelo Evangelho. Quando o 
jornalista Peter Seewald ${ }^{1}$ perguntou ao então Cardeal Joseph Ratzinger, hoje Papa Emérito Bento XVI, se era necessário um modo diferente de transmitir a fé, o Sumo Pontífice respondeu isto:

O que é importante é que o pregador tenha uma relação interior com a Sagrada Escritura, com Cristo, a partir da Palavra viva, e que, como Homem desta época em que vive, e que é a sua, à qual não foge, realmente interiorize a fé. E depois, quando realmente puder comunicá-la a partir de um aprofundamento pessoal, o modo diferente de a comunicar vem por si mesmo (RAZTZINGER, 2005, p. 206).

O Papa Bento, quando estava na função de Cardeal e Prefeito da Congregação para a Doutrina da Fé, nos falou da suma importância de termos a Palavra de Deus assimilada em nós.

Temos a tendência inata de primeiro atirar pedra em tudo e em todos. Criticamos os padres, a nossa Igreja, as estruturas, o Executivo, o Legislativo, o Judiciário, a Câmara, o Senado, as organizações, a política, os políticos, o nosso vizinho, o líder comunitário, enfim, mas efetivamente não pomos a mão na massa, não arregaçamos as mangas e não dizemos "vamos lá, vamos mudar essa situação".

O que você faz para mudar a sociedade? Qual é o seu engajamento na luta para um mundo mais justo, fraterno e irmão? Posto que haja sujeira no mundo (e há muita sujeira, corrupção, violência, drogas, prostituição, pobreza etc.), é nossa culpa; precisamos ser eficazes, lutar contra o descaso, opormo-nos às forças do mal, espirituais e humanas, às ações maléficas dos homens que vão contra as leis de Deus. Ou preferimos resmungar, cruzar os braços, fecharmo-nos numa redoma a lutar? A Palavra de Deus nos diz: "Filhinhos, não amemos só com palavras e de boca, mas com ações e de verdade! Aí está o critério para saber que somos da verdade..." (1Jo 18-19a).

Muito seriamente a Bíblia nos afirma que "Se alguém disser: 'Amo a Deus', mas odeia o seu irmão, é mentiroso; pois quem não ama o seu irmão, a quem vê, não poderá amar a Deus, a quem não vê" $\left(1 J_{o} 4,20\right)$.

Sem o Criador, você não é nada, sequer existe! Você, eu, todo aquele que não assume em espírito e em verdade Jesus Cristo em seu coração vaga pela vida, anda na desgraça, isto é, na ausência da graça, fazendo um bocado de gente sofrer.

1 RATZINGER, Joseph. O Sal da terra: o Cristianismo e a Igreja Católica no século XXI: um diálogo com Peter Seewald. Rio de Janeiro: Imago, 2005, p. 206. 
Falando como tias e avós, "menino, para de sofrer!" Eu conclamo: aceite Jesus! Falando como mãe que, com amor, briga com o filho e lhe diz "já pra dentro de casa, vai tomar banho", e o menininho sai correndo para o chuveiro, e o coraçãozinho da mãe dói, porque corrigir dói em quem é corrigido e em quem corrige os cristãos, digo-vos: "já pra dentro da nossa mãe Igreja Católica, receber Jesus Eucarístico!” E digo mais, "rapa pra fora daqui e vai ser luz para seus irmãos, os doentes, os mendigos, os pobres, os marginalizados e sofridos. Traga-nos de volta, porque o Pai o espera!" Acorde bendito, bendita; acorde para a Igreja Católica: a Igreja de Deus fundada por Jesus Cristo. Como disse São João Roberts, antes de morrer na forca, a frase que os santos padres repetiam nos primeiros séculos: "Fora da Igreja não há salvação". ${ }^{2}$ A Igreja é necessária para a salvação: "Por isso não podem salvar-se aqueles que, sabendo que a Igreja católica foi fundada por Deus, mediada por Jesus Cristo, como instituição necessária, apesar disso não quiserem entrar nela, ou, então, perseverar (LG, 14 retirado de CIC n. 846); acordem para o seu Senhor; venham, acordem!

Pule desse sofá, desse conformismo e vá para os braços de Jesus, porque Ele o ama e quer enchê-lo de bênçãos e graças; fazer de você um homem novo, uma mulher nova, renovados no Seu Santo Espírito.

Jesus, com seu infinito amor, quer nos curar de todos os males que nos afligem. Só com Jesus, você é capaz de transpor os obstáculos da vida; sem Ele, nada somos e podemos.

Seu coração faz tum-tum, tum-tum, tum-tum. Você respira, tem inteligência, memória, vontade, sensibilidade. Anda, come, é capaz de amar? ... Foi o Pai do Céu que permitiu a sua existência: "Foste tu que criaste minhas entranhas e me teceste no seio da minha mãe" $(S l 139,13)$. Você tem valor para Deus, muito valor! Prova-o o fato de Ele ter dado o Seu único Filho para morrer pelos nossos pecados!

Escute com o coração a mensagem de Deus para você:

E agora, assim diz o Senhor, aquele que te criou, Jacó, aquele que te modelou, Israel: "Não tenhas medo que fui eu quem te resgatou, chamei-te pelo próprio nome, tu és meu! Se tiveres de atravessar pela água, contigo estarei e a inundação não te vai submergir! Se tiveres de andar sobre o fogo, não te vais queimar, as chamas não te atingirão! Pois eu sou o Senhor, o teu Deus, o Santo de Israel, o teu

2 AQUINO, Felipe Rinaldo Queiroz de (Org.). A Igreja é sua mãe. In: Jovem, levanta-se! 11. ed. São Paulo, Lorena: Cléofas, 2006, p. 146. 
Forte! Para pagar tua liberdade eu dei o Egito! Para ficar contigo, entreguei a Etiópia e Sabá! Pois é muito precioso para mim e mesmo que seja alto o teu preço, é a ti que eu quero! Para te comprar, eu dou quem for, entrego nações, para te conquistar"! (Is 43,1-4).

Olhe o quanto Deus ama você. Você é a cara d'Ele, imagem e semelhança, herdeiro do Céu, quer mais do que isso? Acima disso não existe!

Com Jesus, temos tudo; absolutamente tudo. Nossa maior riqueza é ter Jesus Cristo como Senhor nosso.

Com Jesus, podemos fazer maravilhas neste mundo. Portanto, vamos pegar a "enxada", invocar o Espírito Santo, rogar pela intercessão de Maria, pedir a intercessão dos Santos, a proteção dos anjos de Deus e, com nossa inteligência, prudência, entendimento, sabedoria, fé e razão, dons do Espírito, e ir, sem medo, converter outros irmãos, anunciando o amor de Deus.

As estruturas que mantêm a sociedade em funcionamento são de alguma forma boas - embora possam e devam ser melhoradas. $\mathrm{O}$ que está faltando são homens bons, convertidos, corações adoradores que, assumindo seus postos, deem o seu melhor, façam o bem para todos, pautados nos princípios bíblicos, sem abrir mão deles! O mundo muda, quando o coração muda.

A frase de Martin Luther King, líder estadunidense que lutou pelos direitos humanos, sobretudo dos negros e mulheres, é profunda e real: "O perigo não é a audácia dos maus, é o silêncio dos bons".

Muitas centenas de pessoas deram suas vidas para fazer deste mundo um lugar melhor e mais irmão. Se o mundo não for irmão, digame o que ele vai ser? S. Paulo diz:

Aquele que diz que está na luz mas odeia seu irmão está nas trevas. O que ama o seu irmão permanece na luz e não corre perigo de tropeçar. Mas o que odeia o seu irmão está nas trevas, caminha nas trevas, e não sabe aonde vai, porque as trevas ofuscaram o seus olhos (1Jo 2,9).

Perguntaria aos homens de inteligência e ciência, aos doutores, sociólogos, economistas, juristas, filósofos, antropólogos, cientistas, políticos, príncipes, reis, enfim, eu lhes perguntaria isto: existe um modelo de sociedade que seja melhor do que o apresentado pelo Homem de Nazaré, Jesus Cristo, o mundo do amor, da paz, da partilha, 
da justiça, do doar-se para fazer o outro feliz? Nunca houve e nunca existirá!

Temos muita capacidade de ajudar a quem sofre; os talentos, para isso, só precisam ser usados. A certeza de que o podemos vem do Espírito Santo. O Espírito Santo é quem infunde em nós essa confiança em Deus e em Suas obras.

A Palavra nos afirma: "Todo o que foi gerado de Deus vence o mundo" ( $\left.1 J_{o} 5,4 \mathrm{a}\right)$. Veja o que Jesus diz aos seus discípulos: "Não fostes vós que me escolhestes; fui eu que vos escolhi e vos designei, para dardes fruto e para que o vosso fruto permaneça. Assim, tudo o que pedirdes ao Pai, em meu nome, ele vos dará" $\left(J_{0} 15,16\right)$. É promessa de Deus que se cumpre!

Jesus diz para todos: "Ide, pois, fazer discípulos entre todas as nações... Ensinai-lhes a observar tudo o que vos tenho ordenado. Eis que estou convosco todos os dias, até o fim dos tempos" (Mt 28,19-20). Não seria necessária mais nenhuma outra palavra. Jesus nos elege, nos convoca a levar a Boa Nova para dentro de nossas casas, condomínio, bairro, cidade, etc. aos cativos, oprimidos, aos doentes da alma e do corpo.

Precisamos amar com um amor gratuito e desinteressado. Só o amor tem essa força de mudar a realidade a nossa volta. O amor é o sustentáculo da raça humana. É a espinha dorsal da existência humana. Sem amor sincero, o homem desfalece, perde suas estruturas enquanto homem. Não havendo homem, não há sociedade, Estado... O homem que não ama é como se não existisse. Duro, não? Pois é. Essa "invenção" foi de Deus. Toda a criação visível (terra, céu, mar, plantas, árvores, enfim) e invisível (nossa alma, os anjos) foi criada por Deus por amor. Deus nos pede algo tão sublime, o maior de todos os dons, mas que, ao mesmo tempo, é tão difícil de dar. Mas "Deus é amor" nos disse S. João, capítulo 4, versículo 16; Ele não pode ser outra coisa fora disso! Por amor, formou-nos, infundiu em nós o amor, e não sossegaremos enquanto não estivermos nesse amor, como diz Santo Agostinho. feliz.

Quem ama é feliz. Quem se dá gratuitamente para o próximo é

Esta é a lei de Deus: a lei do amor. Da mesma forma que se a lei da natureza for descumprida trará problemas, a lei do amor, se quebrada, estacionada, não utilizada, gera o que vemos por aí: uma sociedade fragilizada, desestruturada, deteriorada no seu ser. 
Façamos um contraponto: não são as condições econômicas, sociais, que asseguram aos cidadãos saúde, educação, bem-estar, lazer, entretenimento, segurança, trabalho, renda etc. que saciam a sede de viver das pessoas, tão somente. Veja, estou falando de algo transcendental, existencial, daquilo que aquieta o coração do homem. Alguém pode ter todo o dinheiro do mundo, mas ser uma pessoa triste e vazia no seu interior, sem vida, porque ainda não encontrou o amor. Só o Amor sacia!

O mundo pode virar um EUA economicamente e, no quesito criminalidade e segurança, uma Finlândia, uma Noruega. No entanto, o motor que nos move e nos joga para frente, a fim de viver, é o amor: é amarmo-nos mutuamente. Por questão lógica - ao menos deveria ser - quem verdadeiramente ama, quer dar ao seu próximo saúde física, da alma, psíquica, material e emocional, para o bem-estar do homem e seu equilíbrio.

"Vós sois o sal da terra... Vós sois a luz do mundo" (Mt 4,13-14), disse Jesus. Devemos ser sinal de vida e de amor na vida dos outros; sinal de bondade e de paz, transmissores da paz que vem do próprio Cristo; ser em tudo como Jesus: "tais como é Jesus somos nós nesse mundo" (1Jo 4,17); devemos ser um Jesus na terra. Difícil? Sim, mas possível. Como o faremos? Jesus no-lo disse: "O Defensor, o Espírito Santo que o pai enviará em meu nome, ele vos ensinará tudo e vos recordará tudo o que eu vos tenho dito" (Jo 14,26).

Ponha-se a atender ao chamado de Deus na sua vida. É Deus que realiza todas as obras, mas por meio da nossa cooperação. Deus nos amou primeiro, "não fomos nós que amamos a Deus, mas foi ele que nos amou" $\left(1 J_{o} 4,10\right)$, mas Ele o espera, e conta com você e com seu amor.

O "segredo", a chave, é nos dispormos a encontrar a Deus. Bem, sabemos também que é Ele que nos encontra primeiro e nos seduz: "Tu me seduziste, Senhor, e eu me deixei seduzir!” ( $r r 20,7 a)$.

Aí é que está, se cada um fizer a sua parte, nós veremos com os nossos olhos o que Deus é capaz de fazer!

O Deus do impossível, o Deus que tudo pode fazer precisa do seu 'sim Senhor', para transformá-lo e melhorar o mundo.

Amemo-nos uns aos outros!

\section{Conclusão}

A partir do que foi exposto, fica claro que uma nova sociedade - não transformada da noite para o dia, como uma mágica, mas uma 
construção árdua e diária - é possível. Possível, no entanto, somente a partir de Cristo; sem Ele nada podemos fazer; sem Cristo nenhuma transformação para uma sociedade justa, fraterna, irmã, de amor, será possível. Qualquer tentativa neste sentido fora de Jesus será mero reformismo inepto. Cada um de nós devemos tomar consciência e jogar a responsabilidade de uma transformação para si. Não fique estagnado. Se a maioria não faz nada, seja você a minoria. A partir de sua atitude como cristão é que será possível estimular, animar, encorajar outros cristãos, para que o Reino de Deus seja construído desde agora. Mova-se!

\section{Referências}

AQUINO, Felipe Rinaldo Queiroz de (Org.). Jovem, levanta-se! 11. ed. São Paulo, Lorena: Cléofas, 2006.

BÍBLIA. Português. Bíblia Ave-Maria. 140. ed. São Paulo: Ave-Maria, 2001.

BÍBLIA. Português. Bíblia de Jerusalém. 3. ed., rev. e ampl. São Paulo: Paulus, 2004.

RATZINGER, Joseph. O Sal da terra: o Cristianismo e a Igreja Católica no século XXI: um diálogo com Peter Seewald. Rio de Janeiro: Imago, 2005.

Recebido: 24/03/2014

Avaliado: 02/04/2014 